सF

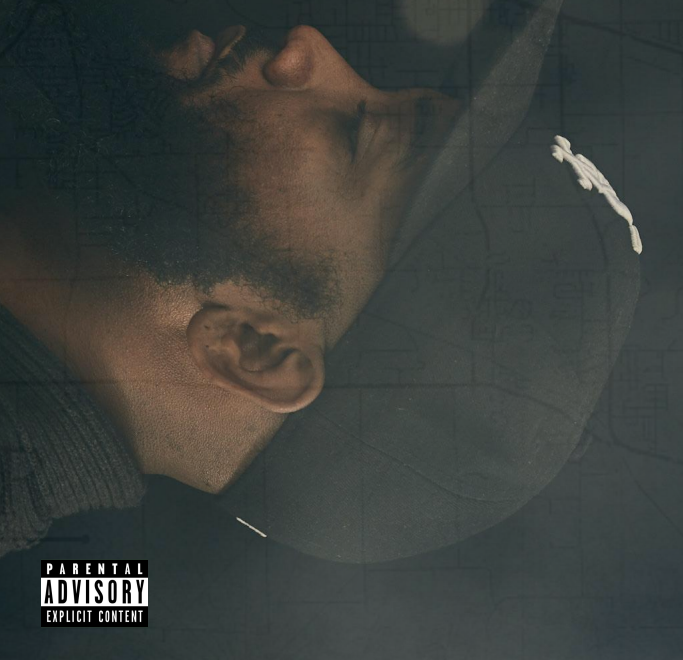




\section{i used to love to dream}

F

Raininin

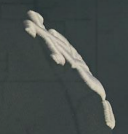

framing pain

decatur, illinois ... ampersand playfields ... crack, usa for you ... just in case stage fright particular activity ... nword gem worth knowing ... ready (feat. truth) asterisk american town ... beats: 052, 058, 059, \& 067 by vintage. 054, 056, \& 063 by marcus "truth" fitzgerald. 064 by deiontrae lawrence mixing: 052, 053, 054, 055, 056 057, 058, 060, 067, \& 065 by a.d. carson. 059 \& 063 by marcus "truth" fitzgerald. 064 by mike moxham mastered by mike moxham

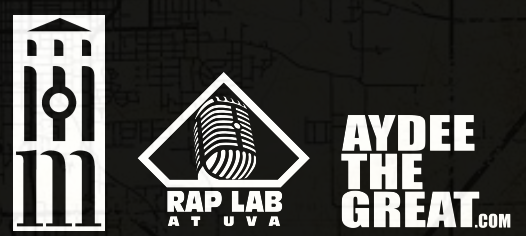




\section{DUGEC}

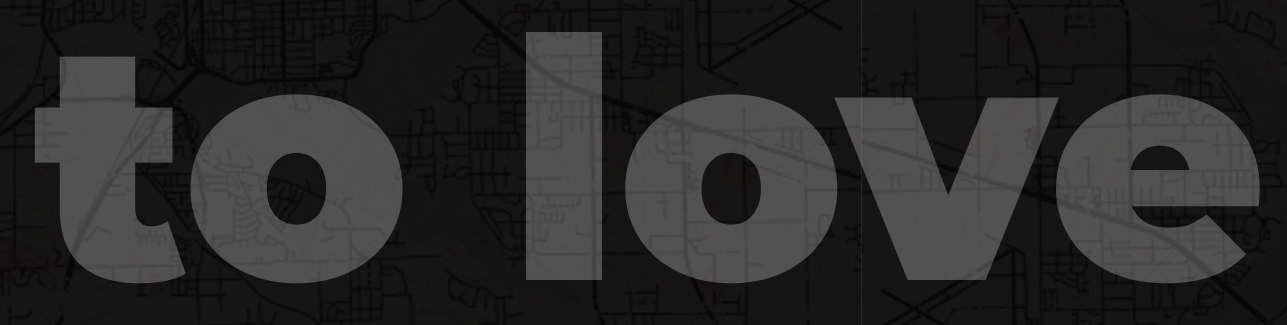

Decatho dreEm 


\section{to love}

to dream is the third in a series of mixtap/e/ssays titled sleepwalking. the title of the series is borrowed from the narrator of ralph ellison's invisible man, who, in the course of describing his acceptance of his "invisible" identity observes, "you're constantly being bumped against by those of poor vision. or again, you often doubt if you really exist" (4).

the narrator continues, "you wonder whether you aren't simply a phantom in other people's minds. say, a figure in a nightmare which the sleeper tries with all his strength to destroy. it's when you feel like this that, out of resentment, you begin to bump people back" (4).

he later states: "i remember that i am invisible and walk softly so as not to awaken the sleeping ones. sometimes it is best not to awaken them; there are few things in the world as dangerous as sleepwalkers. i learned in time though that it is possible to carry on a fight against them the previous two sleepwalking projects focus on local events following my dissertation album, owning my masters: the rhetorics of rhymes \& revolutions, which is a response to \& reflections on living in clemson, south carolina as a graduate student in the university's rhetorics, communication, \& information design phd program. i wrote \& recorded sleepwalking, volume 7: a mixtape during the transition from doctoral student to assistant professor of hip-hop at the university of virginia in charlottesville, va immediately after graduation. the summer of 2017 - filled with white nationalist protests \& local resistance thereto has been called "the summer of hate." i wrote \& recorded sleepwalking 2 in the spring semester of 2018 \& released it at the end of my first year at uva.

\section{i used}

to love

to dream is, among so many other things, about being from decatur, illinois. it's about growing up \& moving away $\&$ wondering if the choices you made were the right ones, 
despite what might be viewed externally as success. \& that's really an evasive way to hone in on a feeling akin to what some people might call "selling out" or "buying in," depending on how we might choose to frame it, \& i think those feelings are ... or can be ... separate from the moral, philosophical, \& ethical dimensions undergirding any internal debate about authenticity or staying true to oneself or to any city or neighborhood. the loneliness \& alienation you might attribute to being away \& trying to remember relationships to home can make a person feel they've betrayed a trust \& therefore deserve those feelings.

i wrote the album to try to more accurately describe that particular loneliness \& alienation that exists in my mind between where i'm from \& where i'm at currently. 


\section{DUGEC}

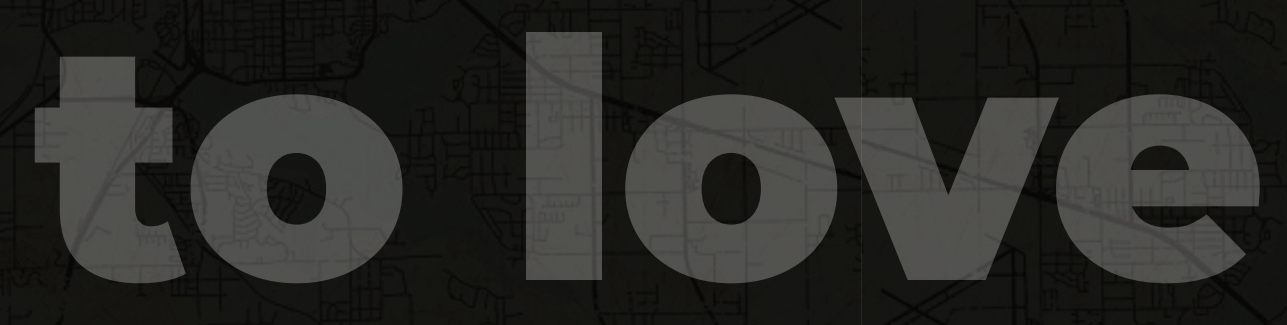

Decatho dreEm 

framing pain [beatby vintage 82 bom]

yes, yes.

just another day in a pretty boring life ... i write, perform like, ignoring hype.

polite like i was born nice.

soar at heights where i don't need to see.

i'm easily the type you peep at night,

\& you don't need to squint, the heat from me is bright.

when i breathe on mics it's like i'm heaving, i won't ever even odds,

i'd rather tweet or blog than be like steven jobs.

i'd rather stay \& laugh than leave \& sob.

i'd rather break the whole machine than try to limit me \& be a cog. when they ask me what i'm trying to preach, i pause.

i tell 'em " $i$ dunno- the difference from a demagogue \& demigod."

king size, but serving minibars,

but i assume if you consume too many

then they'll hit you plenty hard.

they'll say my whole demeanor's been a fraud,

an intricate façade.

won't offer no rebuttals, this is part

of where my newfound vision starts:

a written art comparable to living hard avoiding prison bars. 
collected thoughts, it's like a mini mart,

\& don't want any part

of trendy, artificial, little pity parties

celebrating how i made it

out of unimaginable trauma.

it's the drama that they want,

\& so i honor

what i've come to do \& what i've come into \& what i want to

do.

so what i've brung to you has sprung into a kind of

comfortable

existence i'll call wonderful

if, after i wander through this new terrain,

i've found the way to frame the pain as something new.

\section{[applause]}

... here, close to the center of the united states, the sign on the highway reads "decatur, illinois: population 59,305." from a distance it looks like any other town of its size. its people make their living from factories, stores, offices, railroads, \& surrounding farms just as in many other american communities. When you meet them on main street they look as familiar as anyone's neighbors anywhere in the united states. but go out with them \& you'll begin to sense a difference... 


\section{ampersand [beat byteuth 183 bom:}

yes, yes.

[1] where i'm from, the celebrations are devastating.

change gon' come, but it feels like forever waiting for that dime \& nickel to make a dollar

a lot of it never makes sense.

being easy to b\&e, hope a king never leaves prints.

invented a different life where i take what i see, put it on a line, then make it rhyme.

time never makes it easier.

leave it \& let it go.

but it's there when i close my eyes, even more than it was before,

so ilie.

i be awake on most nights, work in the mornings, rehearsing purpose;

convert it to verses, merciless warnings.

it hurts, \& i feel i'm torn,

even worse when it's in a song.

\& the difference between the then \& the now

is it feels so wrong that i'm here.

yet, here i am—narrator, illustrator,

pro \& antagonist

you'll see a difference later

if you wait to hear me out.

if the mantra's "get the paper,"

\& your dogs be playing fetch,

but catchers call that misbehavior,

the paradox is apparent. $\mathrm{i}$

be wondering the meaning.

meeting me through metaphor

i be humble when i see him 
mumbling my greetings,

staring at my feet like i be nervous.

most evenings

i be staring at a beat \& seeing murder.

i was gifted as a child.

granny listened \& said it.

told me to never bury my talents.

give it \& spread it.

learned from her bible lessons much more than $\mathrm{i}$ give 'em credit.

so, really my synesthesia is more like a sin aesthetic.

[hook] i be knowing i be on some shit i shouldn't. lord forgive me,

but if i could change a thing i probably

wouldn't.

i be putting on a mask, still never smile for cameras,

try to keep the hunger of an amateur,

ampersand

ample ammunition, handle business,

then get little, plan, plot \&

strategize,

\& look out for watching eyes,

occupy the lane i'm in, \& know that even if

i signal

it'll only change what i see in the

rearview.

[2] where i'm at

i don't be knowing the difference between my foes \& my

friends.

i don't pretend, \& i'm cool with not fitting in.

a little more than ten years of sobriety,

plus i try to be healthier.

might as well be aware how they coincide, if it's better.

i be engaging with people, anxious, abstaining, \&, 
some days i really hate i chose therapy over jameson. the polar opposite of myself.

feel like i'm barely him.

but he ain't die, \& i ain't bury him.

the thing they call success is real elusive.

used to boast about "exclusive" shit.

truthfully, i wasn't used to shit.

still ain't,

\& still can't decide if i be bragging cause i'm proud or ashamed

alcohol would chase a doubt when it came.

but now my frame of reference, checking what's a lesson worth the stress,

or if what i used to call hate was just depression with

inflections

i externalized, accepted, then projected on competitors.
\& actually, i ain't too sure i'm better, cause

i be knowing.

[hook] i be knowing i be on some shit i shouldn't. lord forgive me,

but if i could change a thing i probably wouldn't.

i be putting on a mask,

still never smile for cameras,

try to keep the hunger of an amateur,

ampersand

ample ammunition, handle business,

then get little, plan, plot \& strategize,

\& look out for watching eyes,

occupy the lane i'm in, \& know that even if i signal

it'll only change what i see in the rearview.

in decatur they say, "the family that plays together stays together." out in the city's playfields ... 


\section{crack, usa}

... you have whole generations of black folks who are in prison, \& their families have been destroyed. then we have young men \& young women who are grown folks who have suffered through generations of dysfunction because they were targeted by drug policies ...

[1] the setting is crack, united states in the 80's \& in the 90's.

find me under streetlights, these nights, behind me is a gang of angry lookalikes who look just like my pops \& me. my ma was kind of hooked on rolling stones, so who was watching me but me myself \& them?

building with what they called broke. 
products of our environments. that's why we say we dope. \& we was potent.

fitting every description

of the prescription

that was gripping,

pillaging our communities with impunity

\& we was soon to be targeted

for what was marketed

\& sold to us by us.

by "us" i mean u.s., \& lest i be unclear,

objects in the mirror may be nearer than they appear.

if god made sheep to be sheared

$\&$ we was slaughtered,

then the thought of sons \& daughters in this war zone was a conclusion already forgone.

before long,

they selling us our stories back like we had never heard them. like battle scars were proof that we deserved them.

[hook] there's no place like home.

not where i be living.

soon as it get hot, we out the kitchen.

but there's a war going on outside. we ain't safe. behind enemy lines it ain't called friendly fire.

so, when it's hot, we don't call it friendly fire.

you hear shots, but it's never friendly fire.

it's going on outside. nobody's safe behind enemy lines. it ain't called friendly fire.

... from a criminal justice point of view, uh, we're seeing such a different reaction, um, \& it is much more 
empathetic, and, we can protect the victims ...

[2] kinfolks watching for ryus.

you never will win a street fight playing them by rules. so, question number one is, "where you from?"

but we already there.

\& question number two was, "who you knew?"

so, when the news

about the rise on the horizon, \& surprising as it may be,

that all those men women \& babies

were taken with the tides

if they couldn't fly,

swim, or stay afloat.

products of our environment. that's why we say we dope.

\& it's still potent,

fitting every description of the prescriptions that are gripping,

pillaging their communities with impunity.

\& they are eagerly targeted.

what was marketed

\& sold to them by us.

by "us" i mean u.s., \& lest i be unclear,

objects in the mirror may be nearer than they appear.

if god made sheep to be sheared,

\& they were slaughtered,

then the thought of sons \& daughters in this crisis

was a conclusion worthy of fighting.

[hook] there's no place like home.

not where i be living. 
soon as it get hot, we out the kitchen.

but there's a war going on outside. we ain't safe. behind enemy lines it ain't called friendly fire.

so, when it's hot, we don't call it friendly fire. you hear shots, but it's never friendly fire.

it's going on outside. nobody's safe behind enemy lines. it ain't called friendly fire.

... these reforms will also support our response to the terrible crisis of opioid \& drug addiction. never before has it been like it is now. it is terrible...

[liquid pouring]

... for the dudes who ain't here. man, i had so much to tell you. $i$ wrote a poem for you. nigga, i know you don't like poetry, but i'm gonna read it to you anyway.

i ain't never read my poetry for nobody, not even my momma. can't see a damn thing.

it goes ... 


\section{just in case musicloyvintage \\ if $\mathrm{i}$}

die

in police custody, please

ask questions because,

though i sometimes speak out of turn \& ask "why?" more often than some folks care to entertain,

i don't see me leaving an exchange with an officer so

depressed \& disconcerted that it would make me take me away from you.

if you're told i resisted,

please

ask for evidence because

you \& i know i know they're armed with everything from pepper spray to tasers

and,

taking that into consideration, anything that

would

make me move suddenly

or do anything

to escalate their use of force to my own final destination in that moment is less likely than what you'll find to be true.

if they tell you how bad i was before then,

please remain vigilant because

none of my past behaviors should justify me

leaving an interaction with law enforcement with the

ultimate penalty enacted without the due process afforded others in courts of law.

in fact, 
if law enforcement forces those who laws enforced impact,

whose backs \& torsos act as source code

- hacked -

\& more so lack the morals tacked to moral acts,

then go \& ask if my blasting or maiming was more a result of semi-factual blaming

than poor tactical training,

\& whoever's tasked with staffing

\& claiming credit for a job well-done

should be person number one to whom this query is posed.

what i'm asking

is for you to ask,

\& keep asking,

if those sworn to protect \& serve say to you

that, in order to properly execute their duties, it was necessary to execute me,

\& the truth as you know it doesn't match up with the truth you know to be,

it's likely because the truth that's in between the two is too inconvenient for those who have the power to speak it.

\& the way to honor me isn't to turn the other cheek,

it's to ask,

again \& again,

again \& again...

why?

\& i'm telling you,

now,

to ask these questions,

then, 
because it seems to be happening far too frequently \& the trend is forcing me to err on the side of suspicion

\& my only true defense against what may be inevitable, unconscionable as it should be to us all,

is to hold whoever's at fault responsible, even if who's responsible is considered the law.

\section{stage fright}

fear is not real. [yes, yes] the only place that fear can exist is in our thoughts [sometimes ...] of the future. it is a product of our imagination [... sometimes, you just-you just try to get a feeling back.] causing us to fear things that do not, at present, \& may [like now.] not ever, exist.

you are now witnessing

a tamer version of my sickest sins.

there is not a box that i will fit within.

live within the complicated, complex storm after the calm. it's

further explanation of my thicker skin.

listening to nonsense.

this is what my charm gets. 
but i can only hear it

'cause i keep it at an arm's length.

knew they wanted me gone before i came

but i came still.

nothing prepare you for being pressed more than pain will.

game, skill,

preparation, extra patience,

aim, kill,

less debating, check my face \& see

that it ain't changed still.

cold heart.

old art. arthritic pain pills.

show starts.

i can feel the same as when i made real music.

shame. feel foolish

when i stay still doing

what i used to.

try to keep my mind in what i

choose to.

i won't be defined by what confuse you.

even though i am, if i can plan it,

i can shoot through

space like

take flight,

organize, \& plot like it's a stage i

stand on.

act accordingly, \& then i brake like 
breaks might surely lead to brake lights.

filaments \& sentences

with sentiments i fill 'em with:

stage fright.

that is near insanity. [i know.] now do not misunderstand me, danger

is very real, but fear is a choice.

so, turn the music ... [hands up. hands up.

hands up. hands up.]

\& keep it up ... [hands up. hands up.]

we are all telling ourselves a story.

now put your hands ... [hands up. hands up.

hands up. hands up.]

\& keep 'em up ... [hands up. hands up.]

yes, yes.
... a few enthusiasts banded together, then they opened their circle to anyone in town who showed an interest in their particular activity.

it was by this means that decatur's people developed one of the finest gun clubs in the country. 
nword gem

[hook] they say that you should be the change you wanna see.

i'm looking in the mirror,

can't even say if who i see is me.

\& who can tell if that image is what i want or what i've been told,

what i have bought or what i've been sold?

so, i can't really even tell you if it's mine.

no, i can only speak to what i find

\& lose along the way, \& seeing $i$

might move differently \& decide

if history don't repeat then it rhymes.

yes, yes.
[1] back when jay was telling me,

"niggas gon' hate us because they jealous."

i never thought to connect that to how them people

would jail us.

they was coming for us all, them public speeches had failed us, just like them teachers that held us in classes \& tried to tell us

bout the

red, white, blue.

looping heads right through sentences we was reading, being led by noose,

to the gallows

pistols \& bibles, lead-like, too.

aftermath of the scene leave a red bright hue 
on the trees \& the ground,

in the breeze is the sound

of the screams. this account

is a means to announce

allegory to the story that would lead to my route \& can maybe, sort of, explain the degrees of

my doubt.

i wasn't even around when they kicked the door to the ground,

search, then seized, whatever it is they found i wanted to try \& ask him the reason he didn't break,

then i remembered ... he told me it was hate.

[hook] they

say that you should be the change you wanna see. i'm looking in the mirror,

can't even say if who i see is me.

\& who can tell if that image is what $\mathrm{i}$ want

or what i've been told,

what i have bought or what i've been sold?

so, i can't really even tell you if it's mine.

no, i can only speak to what i find

\& lose along the way, \& seeing $i$ might move differently \& decide if history don't repeat then it rhymes.

[2] when he was writing me letters 'bout how it's gon' all get better,

i was still drinking liquor \& wishing that 
that could help me drown.

feeling it can't be right.

inspired me through the wire,

hearing this can't be life,

knowing better than trust what i haven't known to be true,

questioning if a lesson is less if it's not a bruise.

who'd have known a disaster was brewing?

i'm teaching school

while trying to make me a master of arts,

\& my compositions start getting some

recognition.

linking with preme,

thinking through things,

but really skipping ahead.

before that happened, i put my foot on that gas, then i pressed it,

\& when i woke i was living,

\& i was mad.

or that's the way i would choose to remember

losing \& given another shot,

so, i learned to aim with precision,

gained me some vision,

\& told myself that i should learn to listen.

[hook] they say that you should be the change you wanna see.

i'm looking in the mirror,

can't even say if who i see is me.

\& who can tell if that image is what i want 
or what i've been told,

what i have bought or what i've been sold?

so, i can't really even tell you if it's mine.

no, i can only speak to what i find

\& lose along the way, \& seeing $i$ might move differently \& decide if history don't repeat then it rhymes.

[3] after he was released, \& i was out speaking to people asking

'bout how my rapping had turned from a passion to an action

analogous to my crafting a future

after my crash, \& i used it

as a way to not lose me,

what did i gain? it seems the game he was playing

was just a race in that place.

now i'm reacting to starter pistols where i am.

i told my nephew, "they hate you because they jealous." \& wondered if he would ever really understand what i'm saying.

[laughter]

... there's a lively spirit in decatur that makes decatur people worth knowing. for, their town is a town where everybody plays. 
ready (featuring truth)

\section{[1: truth] yeah}

uh. break away the chains. we don't need charms.

with our love, with our knowledge, we don't need arms.

welcome brothers home.

we don't need lawns.

keep the uncles in the house.

we don't need toms.

at the lab in virginia.

all we need: drums,

couple basses \& a sample. finish it in ample.

heavy in our hearts,

make it difficult to handle.

not saying shit

is the breeze against the candle.

so, i chopped it up with dilla pianos \& the sample.

middle of the winter,

but the booth is like orlando

in the middle of the summer.

the visit was an honor

i met a couple game-changing folks

on the come-up, like, 
well-versed in history \& fiction. i'm sitting back thinking, like, this what we been missing.

this should be the mission:

to cash in on the pain.

from laughter \& shame,

the passion remains, cause

[hook: truth] we ready.

we gon' take it. we gon' make it, cause we ready.

we gon' scream it. we gon' play it in our chevies. not a building.

not a body

or a levee.

joe, we ready.

[hook: a.d.] yo, we ready

we gon' rip it,

or we'll tip it

if it's steady.

we gon' lift it even if the shit is heavy.

keep the mission with the vision on the deadly. 
yeah, we ready.

[2: a.d.] ay, yo,

they say there's something special

'bout a black love,

\& if they ain't never had it

then they lack love.

it's like them conversations

in the back of

a mind where it's defined

as being backed up.

yo, if the doors open,

\& we all come though,

\& being here is what it all comes to, it was worth it to share it, i mean, i purposely cherish the very thought of a practice, creating habits to challenge the way to sharpen the steel that'll need itself

to be better at doing what it does.

huh. it's what it always was.

\& what it will be will,

\& if we still be still

then there ain't no way that we'll be killed. huh.

so, i say let's be

\& if i can, let me. 
there's much more

than what the world let see. huh.

so, i say let's be

\& if i can, let me.

there's much more

than what the world let see.

\& we ready.

[hook: truth] we ready.

we gon' take it.

we gon' make it,

cause we ready.

we gon' scream it.

we gon' play it

from our chevies.

not a building. not a body

or a levee.

joe, we ready. uh.

[hook: a.d.] yo, we ready

we gon' rip it,

or we'll tip it

if it's steady.

we gon' lift it even if the shit is heavy.

keep the mission

with the vision

on the deadly. 
yeah, we ready.

huh. yes, yes.

[3: truth] alright.

yeah.

so, you thinking that i'm here 'cause you let me.

it's the system, not the person, that upset me.

let me interject-

when you say that you accept,

i don't care if it's a yes or a no, you gonna get me. uh.
[4: a.d.] huh, unapologetic.

thought it so i said it. want it, so i go \& get it. went it got it, now it's all around us.

talked to truth about it

when it was a dream

\& when it started happening we seen.

[hook: truth] 'cause we ready.

we gon' take it. we gon' make it, cause we ready.

we gon' scream it. we gon' play it 


\section{from our chevies.}

not a building.

not a body

or a levee.

joe, we ready.

[hook: a.d.] yo, we ready

we gon' rip it, or we'll tip it if it's steady.

we gon' lift it even if the shit is heavy.

\section{keep the mission}

with the vision

on the deadly.

yeah, we ready.

yo, we ready. 


\section{asterisk}

naw, \& it ain't even therapy.

it's not even close.

huh.

but it's what i got ...

\& it's for you-

for me, too.

yes, yes.

[1] it's hard to focus.

i know that i should know this,

but that don't really matter, so i wrote

this.

\section{\& i quote, "it's}

better to learn it than leave it all to hope since

the game you playing now don't come with tokens."

some of my folks went

by the wayside, still insisting that they tried.

memories of them late nights

never make it to daylight.

they like

the idea of a nigga saying "fuck it. i'm gone"

but never think that wasn't what i was on.

that's what i say to me

'cause i don't really talk to people

often.

an asterisk i'll add to all my losses.

where you wanna be

\& what you understand will be the cost is something to consider when you off

inventing the life you wanna live,

then the life you gonna live,

$\&$ the life you used to live 
will be incongruent. it's different when you do it than when you thought you knew it.

\section{\& saying who's to blame}

is different than asking who is.

[hook] is it really a win when your team ain't there?

try to get you sleep \& your dreams ain't there.

all you want is to make a little something out of nothing you was given,

\& you know it ain't enough to just be living,

\& you feeling like you going through the motions,

\& it's hitting you like rowing through an ocean,

\& though you probably need a little help, you only say that to yourself.

[2] i don't remember the last night i slept right.

i used to love to dream

about the future i would make for myself

\& other things would make it seem impossible to arrive 'cause many folks ain't make it there,

ain't even see twenty-five before they died.

surviving ain't like we was living at war,

but tell that story to the me i was at age twenty-four,

on that hospital bed,

not even scared that i was thought to be dead.

just prepared with all them "nots" in my head.

like, "you not "bout to live. 
might as well get it out 'fore you gone."

\& i can't say i'm happy that i was wrong.

that's what i think to me,

'cause i don't really talk to people often. an asterisk i'll add to all my losses.

where you wanna be

\& what you understand will be the cost is something to consider when you off inventing the life you wanna live, then the life you gonna live, \& the life you used to live will be incongruent

with now. [hook] is it really a win when your team ain't there?

try to get you sleep \& your dreams ain't there.

all you want is to make a little something out of nothing you was given,

\& you know it ain't enough to just be living,

\& you feeling like you going through the motions,

\& it's hitting you like rowing through an ocean,

\& though you probably need a little help, you only say that to yourself.

is it really a win when your team ain't there?

try to get you sleep \& your dreams ain't there. 
all you want is to make a little something out of nothing you was given,

\& you know it ain't enough to just be living,

\& you feeling like you going through the motions,

it's hitting you like rowing through an ocean,

\& though you probably need a little help,

you only say that to yourself.

... that's what decatur people did. with careful planning \& good spirit, they have worked together to make day-to-day living pleasant, helpful, \& constructive. yes, there is a difference deep inside decatur. from a distance, it looks like any other american town.

it could be your town. 


\section{DUGEC}

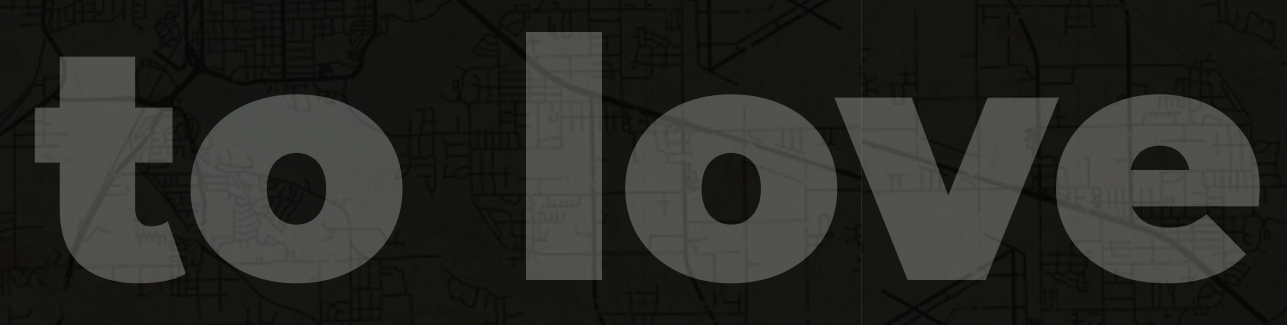

Decatho dreEm 
Albertina Walker \& The Cathedral of Love Mass Choir. "Wash Me and I Will Be Whiter Than Snow (feat. John McNeil)." Glory to His Name. Savoy Records, 1982.

After Earth. Directed by M. Night Shyamalan, performances by Will Smith and Jaden Smith Columbia Pictures, 2013.

Cooley High. Directed by Michael Schultz, performance by Glynn Turman, American International Pictures, 1975.

Caesar, Shirley. "I Believe." Scepter Records, Inc., 1975.

Edwards, Frank, et al. "Risk of Being Killed by Police Use of Force in the United States by Age, Race-Ethnicity, and Sex." Proceedings of the National Academy of Sciences, vol. 176, no. 34, May 2019, pp. 16793-16798. doi:10.1073/pnas.1821204716.

Ellison, Ralph. Invisible Man. Random House, 1952.
Micalizzi, Franco. "M12/M18/M27/M1/M28." Hold-UpIstantanea di una rapina (Original Motion Picture Soundtrack). Carosello Records, 1974.

Mobb Deep. "Survival of the Fittest." The Infamous. Loud Records, 1994

New Birth. "Stop, Look, Listen (To Your Heart)." Birth Day. RCA Records, 1972

"Opioid Crisis vs. Crack Epidemic." POLITICSNATION. Rev. AI Sharpton, Jay Edelson, Vann Newkirk, and Donald Trump. MSNBC, 4 February 2018

Playtown U.S.A. Produced by Film Studios of Chicago and the Athletic Institute of America, New York University Film Library, 1946.

Roelens, Pucchio. "Northern Lights." Rock Satellite. RCA Records, 1977. 
Stebbins, Samuel, and Evan Comen. "These Are the 15 Worst Cities for Black Americans." USA Today, Gannett Satellite Information Network, 27 Feb. 2019,

https://www.usatoday.com/story/money/2018/17/16/racialdisparity-cities-worst-metro-areas-black-americans/3846 0967/.

Wildman Steve. "Oakland, Calif." Eatin' Ain't Cheatin'. Laff Records, 1973 


\section{acknowledgements}

they say to give

people they flowers while they can smell 'em, and say the things you want 'em to hear while you can tell 'em.

\section{so, if you ever}

listened to a song, came to see a live show, took a class, read a poem,

bought a book, you might know

i appreciate your time,

and thanks for your attention.

i maybe never said it,

but know i always meant it. know $i$ always sent it from the place that's sincere,

and since there's no other way, then i'll reiterate it here.

thanks for your patience while $i$ been making my shift from

where $i$ was to where $i$ still want

to go.

and many thanks for the motivation that made the waiting worth it.

i can't relate to perfect.

but $i$ can state these words with a certainty that verses versus me

have me virtually free

from the version i'm afraid of 
and gratitude really matters to

form the habits of

the person i'm a be

from the person i was made from.

with sincere appreciation,

i just wanted to write this to say thank you.

gratitude is my attitude.

i don't always say a lot,

but i ain't mad at you.

i not only want to say it.

i wanted you to have it and to play it.

so,

with sincere appreciation, i just want to give you this, and say thanks...

to everyone \& everything that had any part in making this project possible,

to my family: my mother \& father, kathleen fuller \& tyrone carson,

to my siblings: stew, ju, kris, santrell, jessica, stefon, \& stephanie,

to my shaw \& carson families, r.i.p. emma shaw, alice carson, jamal love \& devin slater,

to friends \& collaborators: marcus "truth" fitzgerald, blake "preme" wallace, chenjerai "bad dreams" kumanyika, \& miguel "mig" martinez, angela simone, mike moxham, vintage, deiontrae lawrence, munier nazeer, mark walcott, to friends \& listeners: shaun atkinson, carmella braniger, edith dulap, erin hughes, veronica mosby, demetrius 
"d-noble" noble, brian nolen \& nolen entertainment group, aaron "chucho" perez, e kehinde thurman,

jillian weise,

to university of michigan press, loren kajikawa, sara cohen, \& mary francis,

to university of virginia colleagues, students \&

friends: jason bennett, meredith clark, ted coffey,

ashon crawley, komi galli, jim igoe, basile koechlin, noel lobley, ryan maguire, karl hagstrom miller, lindsey shavers, emma terry, lisa woolfork, \& the whole rap lab crew,

to the black power station crew in makhanda, south africa: xolile " $x$ " madinda, mxolisi "biz" bodla, cherra, bliss, nomalanga mkhize, \& rushay booysen, to writer's block records: jay young \& ryan "dj rynski" walker,

to eric oren, 3cavaliers uva, uva arts, university of virginia college and graduate school of arts \& sciences, university of virginia department of music, national humanities center, \& the bridge progressive arts initiative,

to charlottesville, virginia,

to decatur, illinois,

\& to dreaming ... 

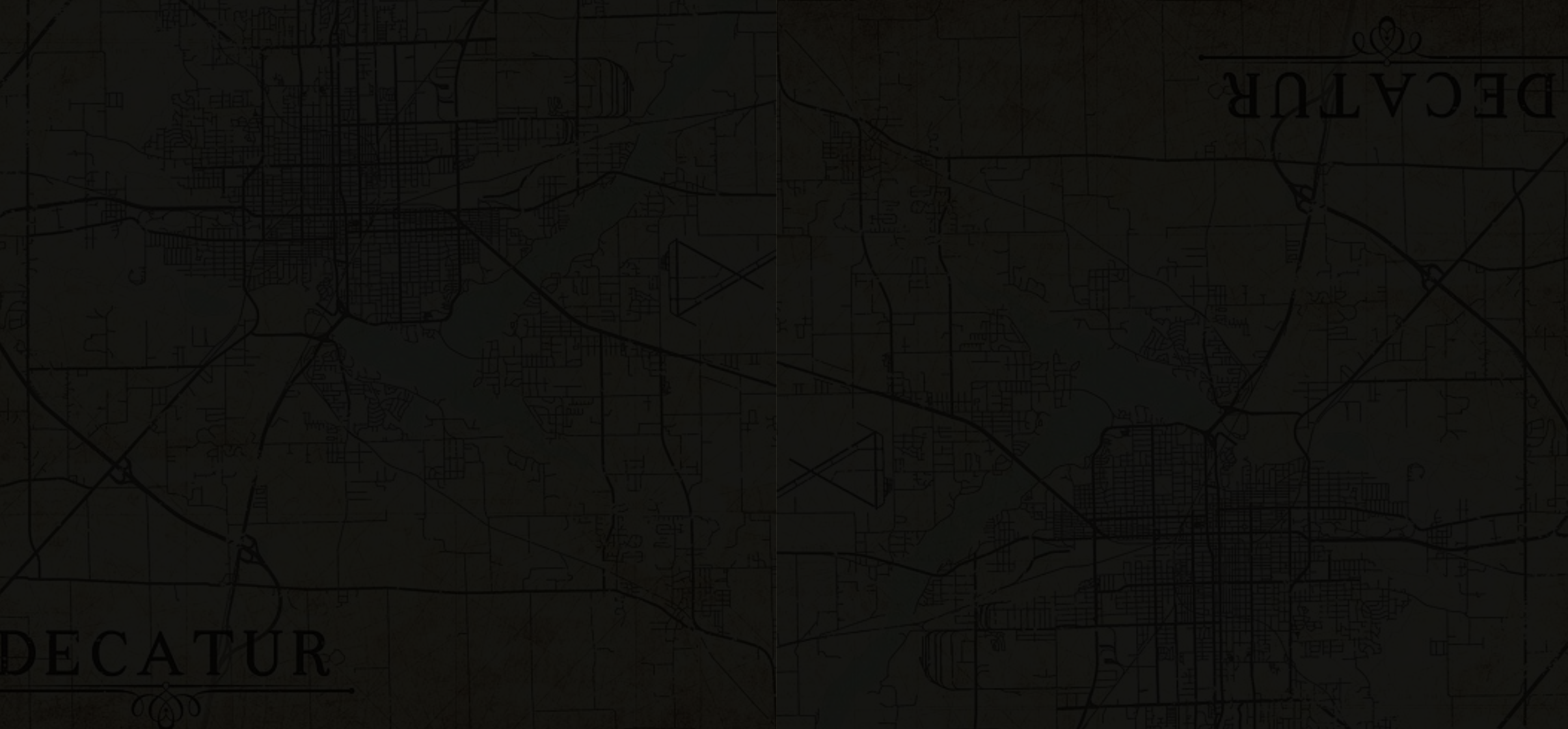

(8) 


\section{i used to love to dream}

F

Raininin

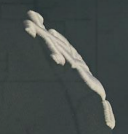

framing pain

decatur, illinois ... ampersand playfields ... crack, usa for you ... just in case stage fright particular activity ... nword gem worth knowing ... ready (feat. truth) asterisk american town ... beats: 052, 058, 059, \& 067 by vintage. 054, 056, \& 063 by marcus "truth" fitzgerald. 064 by deiontrae lawrence mixing: 052, 053, 054, 055, 056 057, 058, 060, 067, \& 065 by a.d. carson. 059 \& 063 by marcus "truth" fitzgerald. 064 by mike moxham mastered by mike moxham

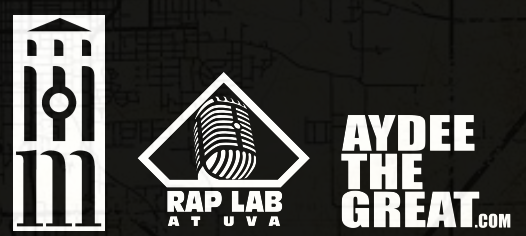

